COMMENT. The authors concluded that despite a relatively small risk of ischemic stroke, smoking and the use of oral contraceptives should be discouraged or limited in young women with migraine. It was not known whether the increased risk of stroke related to all young migrainous women or only to a subgroup that remains to be defined.

\title{
HEADACHE AND GINSENG-RELATED CERBRAL ARTERITIS
}

A 28-year-old woman who had a severe headache after ingesting a large quantity of ethanol-extracted ginseng was diagnosed with cerebral arteritis in the Department of Neurology, Chang Gung Memorial Hospital, Keelung, Taiwan. Ginseng root $25 \mathrm{gm}$ stewed in rice wine was taken for fatigue associated with sore throat. An explosive headache with nausea and vomiting developed 8 hours later and was temporarily relieved by acetaminophen. Smaller quantities of ginseng had never caused headache. CT showed increased density over the falx, suggestive of subarachnoid hemorrhage. Cerebral angiograms revealed multiple areas of alternating focal constriction and dilatation (beading) in anterior and posterior cerebral arteries and superior cerebellar artery, consistent with arteritis. The headache gradually resolved within 10 days. (Ryu S-J, Chien Y-Y. Ginseng-associated cerebral arteritis. Neurology April 1995;45:829-830). (Reprints: Dr Shan-Jin Ryu, Department of Neurology, Chang Gung Memorial Hospital, 199, Tung Hwa North Road, Taipei 105, Taiwan).

COMMENT. The temporal association between the ingestion of the ethanolic ginseng extract and the onset of a severe headache was strongly suggestive of a causal relationship. The use of cocaine, amphetamine, phenylpropanolamine, and other sympathomimetic drugs was denied. Most ginseng users are not medically supervised, and adolescents and adults may be experimenting with doses larger than those generally recommended in Chinese practice $(0.5$ to $2 \mathrm{gm})$. The expected benefits are listed as prevention of aging or tiredness, improved stamina or concentration, and increased resistance to stress or disease.

\section{FEBRILE SEIZURES}

\section{IBUPROFEN AND ACETAMINOPHEN ANTIPYRETIC EFFICACY}

The antipyretic efficacies of ibuprofen $(5 \mathrm{mg} / \mathrm{kg}$ dose $)$ and acetaminophen ( $10 \mathrm{mg} / \mathrm{kg}$ dose) were compared in 70 outpatients (mean age, 2.1 years) with a history of febrile seizures by a randomized, multiple dose, double-blind clinical study conducted at the University Hospital, Sophia Children's Hospital, and Erasmus University, Rotterdam, the Netherlands. Doses were given every 6 hours for 1 to 3 days, and rectal temperatures were recorded at $0,2,4,6,12$, and 24 hours after the first dose. Ibuprofen reduced fever 0.5 degree $C$ more than acetaminophen at 4 hours. The mean temperature was 0.26 degrees lower during ibuprofen treatment, and the highest temperature was 0.3 degrees lower. In a crossover trial and analysis, these differences in temperature were 0.66 and 0.36 , respectively, in favor of ibuprofen. (Van Esch A et al. Antipyretic efficacy of ibuprofen and acetaminophen in children with febrile seizures. Arch Pediatr Adolesc Med June 1995;149:632-637). (Reprints: Dr Van Esch, Department of Public Health, Room Ee2091, Erasmus University, PO Box 1738, 3000 DR Rotterdam, the Netherlands). 